\title{
Utilization of Nano-Grain Size Particles of Natural Perlite Rock in Blended Cement-Part II: Durability Against Sulfate Attack
}

ISSN: 2576-8840

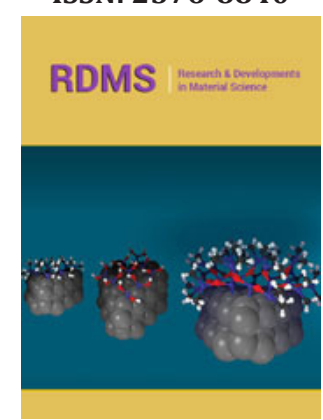

*Corresponding author: Darweesh HHM, Department of Refractories, Ceramics and Building Materials, National Research Centre, Egypt

\section{Submission: 監 August 25, 2020}

Published: 制 September 18, 2020

Volume 14 - Issue 2

How to cite this article: Darweesh HHM. Utilization of Nano-Grain Size Particles of Natural Perlite Rockin Blended Cement-Part II: Durability Against Sulfate Attack. Res Dev Material Sci. 14(2). RDMS.000831. 2020. DOI: 10.31031/RDMS.2020.14.000831

Copyright@ Darweesh HHM. This article is distributed under the terms of the Creative Commons Attribution 4.0 International License, which permits unrestricted use and redistribution provided that the original author and source are credited.

\section{Darweesh HHM*}

Department of Refractories, Ceramics and Building Materials, National Research Centre, Egypt

\begin{abstract}
The chemical resistance or durability of Portland cement pastes (PSO) incorporating natural Perlite rock (PT) against the aggressive attack of 4\% MgSO4 solution up to 12 months were investigated. Results showed that water of consistency and setting times (initial and final) are elongated. The compressive strength slightly improved during the early ages of immersion only up to three months with the blank cement batch (Pp0), but up to 4, 5, 6 and 7 months with cement batches (Pp1-Pp4) containing 5, 10, 15 and $20 \mathrm{wt} \% \mathrm{PT}$, respectively and then decreased. Thereafter, certain deleterious or detrimental reactions started till forming high levels of ettringite and/or gypsum. These new phases are responsible for the decrease of compressive strength. Both combined water and total sulfate contents increased with time of immersion up to 12 months but decreased with PT content if compared with those of the blank (Pp0). The blank cement pastes $(\mathrm{Pp} 0)$ recorded the highest values of total sulfate content, i.e. it is very sensitive to S042- ions. At the end of the 12th month of immersion, the S042- ions only precipitated on the external and lateral surfaces of the hardened cement pastes, and some horizontal minor cracks and little deformation could be seen on the edges of specimens with samples containing PT, whilst large swelling was noted with cement pastes of the blank (Pp0).
\end{abstract}

Keywords: OPC; PT;Sulfate attack;Strength;Ettringite;Gypsum;Sulfate content

\section{Introduction}

\section{Scope of the problem}

The use of nanomaterials as nano-alumina, nano-silica and generally nanoparticles could significantly increase their mechanical properties and durability owing to the reduction in the total pore structure of cement-based materials [1]. Nano silica, which is one of the earliest nanomaterials applied in cement-based composites, had a more obvious and evident effect on the performance improvements compared to other nanoparticles. This is due to that the nano-silica had a high pozzolanic reactivity with $\mathrm{Ca}(\mathrm{OH})_{2}$ in cement composites to create more hydration products or $\mathrm{CSH}$ and/or CAH-gels. Thereby, it is making the composites more compacted [2-4]. Generally, there are two types of sulfate attack can occur. The first is often accompanied by the formation of gypsum in the cement pastes with low $\mathrm{C}_{3} \mathrm{~A}$ immersed in high sulfate concentrations which is the first factor for the formation of ettringite. The second is characterized by the formation of ettringite $\left(\mathrm{C}_{3} \mathrm{~A} \cdot 3 \mathrm{CaSO}_{4} \cdot 32 \mathrm{H}_{2} \mathrm{O}\right)$, in the cement pastes with high $\mathrm{C}_{3} \mathrm{~A}$ immersed in low sulfate concentrations which is the first step of deterioration. The transition between the two types of sulfate attack was gradual, where both ettringite and gypsum could simultaneously occur. The formation of ettringite always leads to expansion, while gypsum usually leads to the loss of cohesion and softening, but no more to a marginal degree of expansion. The loss of cohesion is more directly due to the incorporation of sulfate ions into the CSH and / or CAH-gels [5-8].

The influence of these aggressive media on the behavior of building materials is a topic of significant interest for durability of cement structures [7-12]. This problem could be overcome or at least reduced by the use of mineral admixtures in cement to improve the strength development by the modification of the microstructure of the cement. The use of these cements is well accepted due to the resulting savings through the conservation of energy and cement as well as the production of low-lime products with good mechanical properties and durability [10-14]. The most common types of mineral admixtures are Granulated Blast Furnace Slag (GBFS), Fly Ashes (FA), Silica Fume (SF), Sugar Cane Bagasse Ash (SCBA), Palm 
Ash (PA), Saw Dust Ash (SDA), Sun Flower Stalk Ash (SFSA), Corn Stalk Ash (CA) and wheat straw ash [15-17] which are coming from the various sectors of industry are pozzolanic materials [15-23].

When the pozzolanic materials dispersed into the cement paste, they generate a large number of nucleation sites for the precipitation of the produced hydration products. Hence, this mechanism makes the paste more homogeneous and denser as for the distribution of the finer pores due to the pozzolanic reactions between the amorphous silica and $\mathrm{Ca}(\mathrm{OH})_{2} \mathrm{H}$ formed during the normal hydration process of cement. This positively affects the resistance of concrete $[6,7]$. So, it is not surprising that some advances in cement and concrete technology have occurred as a result of three driving forces: the speed of construction, durability of concrete and environmental friendliness of industrial materials [22-26]. The sulfate attack has been reported to cause a damage of concrete for over a century. The media containing sulfate ions lead to the aggressive attack of cement pastes, mortars and concrete. Some constituents of the cement can enter into some deleterious reactions with these ions [5-8]. At least, six types of reactions could be described by sulfate attack. The most common of which often used to explain the defined sulfate attack are ettringite and gypsum formation.

The addition of supplemental cementitious materials such as Fa, GbfS and SF could improve the mechanical properties and durability of cement-based materials [27-29]. In Turkey, there are about 7500 million tons of perlite deposits, and this represents the $2 / 3$ of it exists all over the world [30]. Perlite is a glassy volcanic rock that contains about $70-75 \% \mathrm{SiO}_{2}$ and $12-18 \% \mathrm{Al}_{3} \mathrm{O}_{2} .2-6 \%$ of its combined water content causes its expansion till become a cellular material of an extremely low bulk density when heated to about $900{ }^{\circ} \mathrm{C}$. Hence, the expanded perlite can be used in various constructional, horticultural and industrial applications [31,32].

Due to its glassy structure and high $\mathrm{SiO}_{2}$ and $\mathrm{Al}_{2} \mathrm{O}_{3}$ contents, perlite acts as a pozzolan. Though its pozzolanic properties have been mentioned in some technical papers [30-32], no investigation has so far been made on the use of natural perlite in manufacturing blended cements. Some advantages can be achieved with perlite blended cement as: the reduction in OPC consumption, improved workability, lower permeability, higher strength, etc. The reduction in OPC consumption helps to decrease the $\mathrm{CO}_{2}$ emission and the cost due to the lower energy consumption during grinding and calcination. Since more than $50 \%$ of the total electrical energy consumption during cement production can be saved [7,33]. The natural perlites are easily grindable, have pozzolanic properties and the cements containing these perlites conformed to the standard specifications for blended cements.

\section{Objectives of the study}

In Part I [32], the physical and mechanical properties of Portland cement pastes incorporated natural perlite rock dust (PT)) were investigated. So, the main objective of the current study (Part II) is to evaluate and focused on the influence of $4 \% \mathrm{MgSO}_{4}$ solution on the durability of Portland cement pastes containing the natural perlite rock dust (PT) up to 12 months of immersion.

\section{Experimental}

\section{Raw materials}

The raw materials used in the present study are Ordinary Portland cement (OPC, Type I- CEM I 42.5R)) and perlite (PT). The OPC sample was supplied from Sakkara cement factory, Giza, Egypt, and its commercial name is known as "Asmant El-Momtaz", while the PT sample was received from the Egyptian Company for manufacturing Perlite and Vermiculite, Egypt having a grain size of about 200 mesh sieves, i.e. $\approx 63 \mu \mathrm{m}$ (Figure 1). The blaine surface area of the OPC was $3400 \mathrm{~cm}^{2} / \mathrm{g}$. The chemical analysis of the starting raw materials is shown in Table 1. The mineralogical composition of the OPC sample is given in Table 2 .

Table 1: Chemical analysis of the OPC and PT samples using XRF method, \%.

\begin{tabular}{|c|c|c|}
\hline Oxides Materials & OPC & PT \\
\hline L.O.I & 2.64 & 1.11 \\
\hline $\mathrm{SiO}_{2}$ & 20.12 & 74.85 \\
\hline $\mathrm{Al}_{2} \mathrm{O}_{3}$ & 5.25 & 10.12 \\
\hline $\mathrm{Fe}_{2} \mathrm{O}_{3}$ & 1.29 & 1.26 \\
\hline $\mathrm{CaO}$ & 63.13 & 0.58 \\
\hline $\mathrm{MgO}$ & 1.53 & 0.04 \\
\hline $\mathrm{MnO}$ & 0.36 & 0.07 \\
\hline $\mathrm{Na}_{2} \mathrm{O}$ & 0.55 & 0.08 \\
\hline $\mathrm{K}_{2} \mathrm{O}$ & 0.3 & --- \\
\hline $\mathrm{P}_{2} \mathrm{O}_{5}$ & 0.19 & 5.13 \\
\hline $\mathrm{SO}_{3}$ & 2.54 & ---- \\
\hline Blaine surface area, $\mathrm{cm}^{2} / \mathrm{g}$ & 3400 & $62 \mu \mathrm{m}$ \\
\hline
\end{tabular}

Table 2: Mineralogical composition of the OPC sample, mass \%.

\begin{tabular}{|c|c|c|c|c|}
\hline \multirow{2}{*}{ Phase Material } & $\mathrm{C}_{3} \mathrm{~S}$ & $\beta-\mathrm{C}_{2} \mathrm{~S}$ & $\mathrm{C}_{3} \mathrm{~A}$ & $\mathrm{C}_{4} \mathrm{AF}$ \\
\cline { 2 - 5 } & 46.81 & 28.43 & 5.9 & 12.56 \\
\hline
\end{tabular}

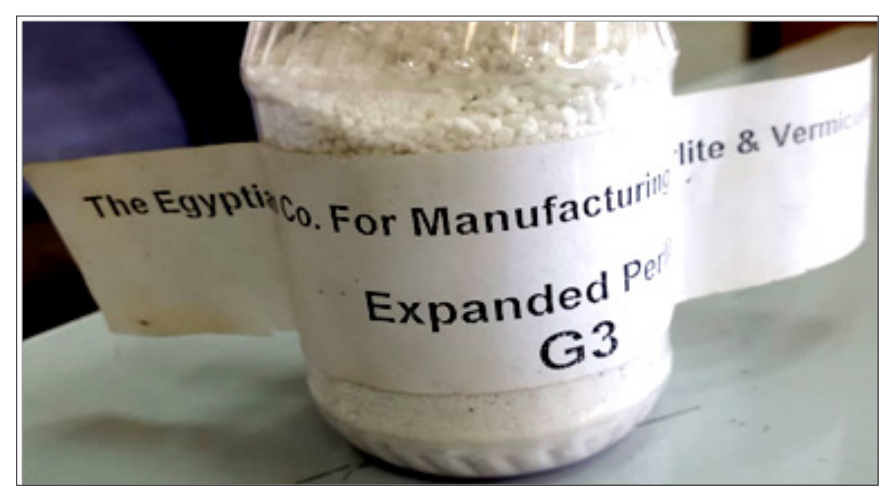

Figure 1: The perlite rock sample (PT). 


\section{Preparation and methods}

Table 3: Cement batch composition, density, $\mathrm{g} / \mathrm{cm} 3$ and fineness, $\mathrm{cm} 2 / \mathrm{g}$ of all cement batches.

\begin{tabular}{|c|c|c|c|c|c|}
\hline \multirow{2}{*}{ Type of Cement } & Materials Batches & OPC, Wt. \% & PT, Wt. \% & Fineness, $\mathbf{c m}^{2} / \mathbf{g}$ & Density, $\mathbf{g} / \mathbf{c m}^{3}$ \\
\hline & P0 & 100 & --- & 3350 & 2.3205 \\
\cline { 2 - 6 } & P1 & 95 & 5 & 3764 & 2.1043 \\
\cline { 2 - 6 } & OPC & 90 & 10 & 4100 & 1.9705 \\
\cline { 2 - 6 } & P2 & 85 & 15 & 4445 & 1.9546 \\
\cline { 2 - 6 } & P4 & 80 & 20 & 4670 & 1.9231 \\
\hline
\end{tabular}

The cement batches are given in Table 3, which also contains the fineness and density of the whole cement batches. Figure 2 illustrates the relationship between the dry fineness and density of the various cement batches (Pp0-Pp5). It is clear that as the PT content increased in the blank cement batch (Pp0), the fineness of the cement batch increased too. The physical and mechanical properties of Portland cement blended with different ratios of PT were previously investigated in Part I [32]. In the present Part II, the resistance of the Portland cement pastes blended with perlite (PT) against $4 \% \mathrm{MgSO}_{4}$ was evaluated and compared with those of the blank cements (Pp0). There are six cement blends for OPC as 100:0, 95:5, 90:10, 85:15, 80:20 and 75:25 having the symbols of Pp0, Pp1, Pp2, Pp3, Pp4 and Pp5), respectively. The blending process was mechanically made in a porcelain ball mill containing three balls for one hour to assure the complete homogeneity of all batches. Before casting of cement cubes, all moulds were oiled with a thin film of motor engine oil, to facilitate the release of the cubes from the moulds during the de-moulding. During casting of cement pastes, a certain percentage of Na-lignosulphonate admixture was added to all cement mixtures during mixing to avoid the agglomeration of the nanoparticles of cement powder. Sodium Lignosulfonate Admixture (SLA) was applied due to its higher activity than other conventional ones (Figure 3). Each already prepared oil moulds was filled with the premixed cement composite and rammed 10 minutes to remove all air bubbles tapped within the mixture. The moulds were filled to the top surface and smoothed with a suitable flat stainless-steel trowel or spatula to obtain a flat and smooth surface [34].

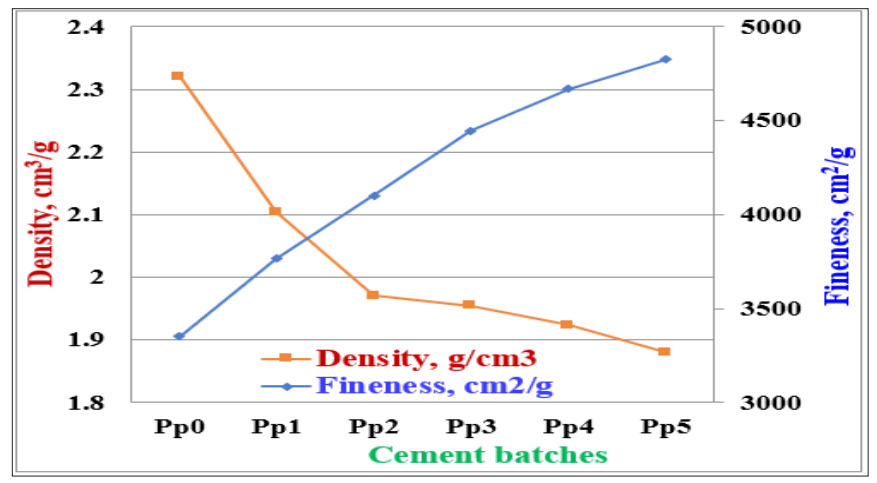

Figure 2: Relationship between the fineness and density of the various cement batches.

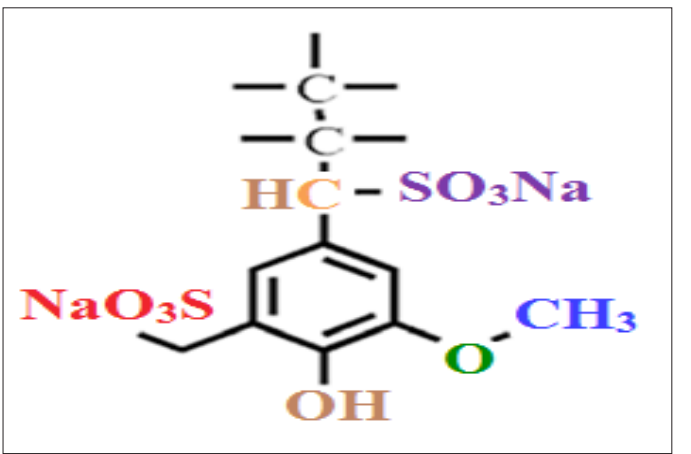

Figure 3: The chemical structure of sodium lignosulphonate.

The standard water of consistency as well as setting time $[35,36]$ of the prepared cement pastes were directly determined by Vicat Apparatus (Figure 4) as follows:

$$
W C, \%=A / C \times 100 \longrightarrow(1)
$$

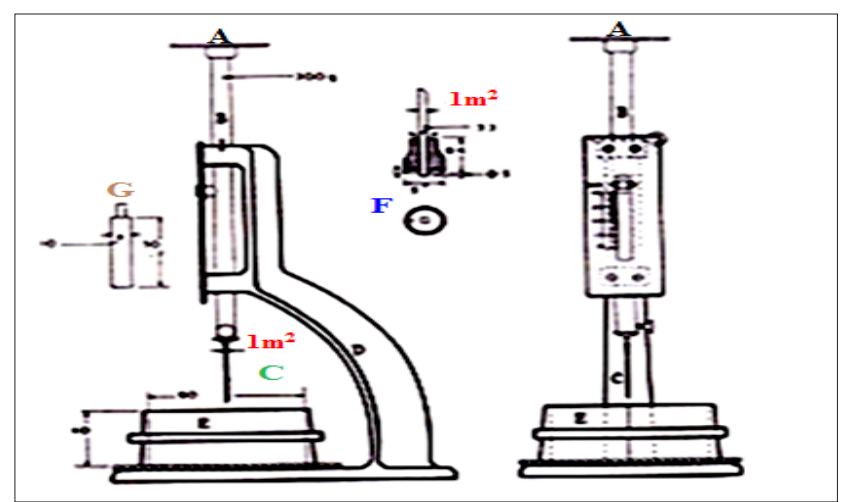

Figure 4: Vicat Apparatus for water of consistency and setting times.

Where, WC, A and C are the amount of water of consistency, the amount of water taken to produce a suitable paste and the amount of cement (300g), respectively.

The cement pastes were mixed using the predetermined water of consistency, then molded into one-inch cubic stainless steel moulds $\left(2.5 \times 2.5 \times 2.5 \mathrm{~cm}^{3}\right)$, vibrated manually for five minutes, and then on a mechanical vibrator for another five minutes. After 
casting of all cement cubes, they were covered with a black wet sheet for the first 24 hours to prevent moisture loss. The moulds were kept inside a humidity cabinet for 24 hours at $23 \pm 1{ }^{\circ} \mathbf{C}$ and $100 \%$ R.H., de-molded in the next day and soon cured under water up to 28 days. The measured values at 28-days for combined water and compressive strength as well as chloride and sulfate contents for each cement mix were considered as zero readings. The compressive strength [37] was carried out and the loading was applied perpendicular to the direction of the upper surface of the cubes as follows:

$$
C S=L(K N) / S a\left(\mathrm{~cm}^{2}\right) K N / \mathrm{m}^{2} \times 10^{2}\left(\mathrm{Kg} / \mathrm{cm}^{2}\right) / 10.2(\mathrm{MPa}) \longrightarrow(2)
$$

Where, $\mathrm{L}$ and Sa are the load taken and the surface area, respectively. The rest of samples were then immersed in a freshly prepared $4 \% \mathrm{Mgcl}_{2}$ and $4 \% \mathrm{MgSO}_{4}$ for 12 months. At first, the chloride and sulfate solutions were renewed every 2-3 days so as to keep its concentrations nearly constant.

After carrying out the compressive strength, about $10 \mathrm{~g}$ of the broken samples was dried at $105^{\circ} \mathrm{C}$ for one hour, and then were placed in a solution mixture of 1:1 methanol: acetone to stop the hydration at any interval, and then kept in an airtight bottle $[35,36]$. The combined water content $\left(\mathrm{CW}_{\mathrm{n}}\right)$ of the hydrated samples was determined on the basis of ignition loss at $1000{ }^{\circ} \mathrm{C}$ for 30 minutes soaking time [37-39] as follows:

$$
C W_{n}, \%=W_{1}-W_{2} / W_{2} \times 100 \longrightarrow(3)
$$

Where, $\mathrm{CW}_{\mathrm{n}}, \mathrm{W}_{1}$ and $\mathrm{W}_{2}$ are combined water content, weight of sample before and after ignition, respectively.

The total sulfate content [5-7] was determined by placing one gram of the dried sample $\left(\mathrm{W}_{1}\right)$ in a beaker containing $300 \mathrm{ml}$ freshly prepared half saturated lime water. The content was stirred for one hour using a magnetic stirrer and then filtered through a sintered glass funnel G. 4. The residue was washed several times with lime water and then with distilled water. Add $5 \mathrm{ml}$ conc. $\mathrm{HCl}$ acid (Sp. gr. 1.18) and drop wise $10 \mathrm{ml} \mathrm{BaCl}_{2}(100 \mathrm{~g} / \mathrm{l})$ to the boiling filtrate. The mixture was boiled gently for 5 minutes, let to cool gradually, and then filter. Wash several times with hot distilled water till free from chloride. Thus, the total sulfate content precipitated. Ignite the residue up to $850{ }^{\circ} \mathrm{C}$ for 30 minutes, cool in a desiccator and weigh $\left(\mathrm{W}_{2}\right)$. The total sulfate content was calculated from the following relation:

$$
\mathrm{SO}_{3} \%=M_{2} \times 34.3 / M_{1} \times 100 \longrightarrow(4)
$$

Where, $M_{1}$ is the weight of the original sample, $M_{2}$ is the ignited weight of the residue and 34.3 is the molecular ratio of $\mathrm{SO}_{3}$ to $\mathrm{BaSO}_{4}$ (0.343) multiplied by 100 .

\section{Results and Discussion}

\section{Water of consistency}

The water of consistency and setting times (initial and final) of the various cement pastes with and without perlite (Pp0-Pp5) are shown in Figure 5. The water of consistency of the OPC (Pp0) pastes was found to be $28.65 \%$. This ratio tended to increase gradually with the increase of PT content. This is mainly attributed to the gradual increase of the specific surface area or fineness of all batches (Pp0-Pp5) with PT content. This is certainly responsible for the high-water demand during mixing. Despite of Na-lignosulfonate admixture, the water of consistency increased due to the high atmospheric temperature during testing $[7,9,39]$.

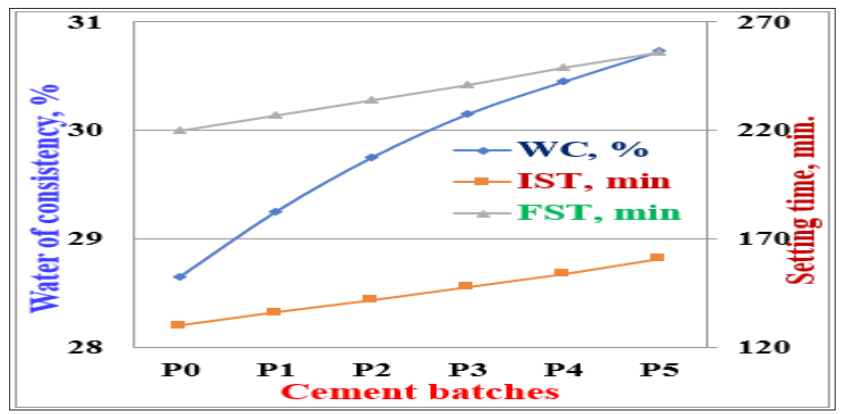

Figure 5: Water of consistency and setting times of Portland and slag cement pastes containing perlite (PT).

On the other hand, the initial and final setting times of the various cement pastes with and without perlite of Portland cement (Pp0-Pp5) were also increased with PT content. The elongation of setting times is often contributed to the higher $\mathrm{w} / \mathrm{c}$ ratios taken to produce suitable cement pastes [5,7,9,39]. In spite of the decrease of the cement portion responsible for the setting and hardening of the cement pastes, the setting times enhanced. This is because the OPC has a faster setting and hardening properties than the PT. Furthermore, this may be attributed to the complex pozzolanic reactions of the PT constituents with the evolved $\mathrm{Ca}(\mathrm{OH})_{2}$ from the hydration of $\mathrm{C}_{3} \mathrm{~S}$ and $\boldsymbol{\beta}-\mathrm{C}_{2} \mathrm{~S}$ of Portland cement forming some additional $\mathrm{CSH}$ and/or $\mathrm{CAH}$. Therefore, the setting is retarded $[5,7,9,32,39]$.

\section{Combined water content}

The combined water contents of the various cement pastes with and without perlite of Portland cement (Pp0-Pp5) are shown in Figure 6. With the OPC cement pastes (Pp0), the combined water contents increased only up to 3 months of immersion, and then decreased up to 12 months. The cement pastes with 5, 10, 15 and $20 \%$ PT content (Pp1-Pp4), the combined water increased up to 4, 5, 6 and 7 months, and then declined onwards. With the cement pastes containing 25\% PT (Pp5), the combined water content enhanced up to 4 months, and then decreased. The increase of the combined water content is principally attributed to the activation effect of the nano silica from the PT, and moreover to the pozzolanic activity of PT with the produced free lime or $\mathrm{Ca}(\mathrm{OH})_{2}$ due to the normal hydration process of the cement forming additional CSH and/or CAH $[5,7,18,20,21,26]$. The decrease of combined water contents is mainly attributed to the aggressive attack of $\mathrm{SO}_{4}^{-2}$ ions that often spoiled the produced hydration products [28,29,40-43]. The optimum cement batch was Pp4 containing 20\% PT because it exhibited the highest results of combined water contents at 
all immersion times up to 12 months. The higher amounts of PT content must be avoided because it recorded the lowest results of combined water contents.

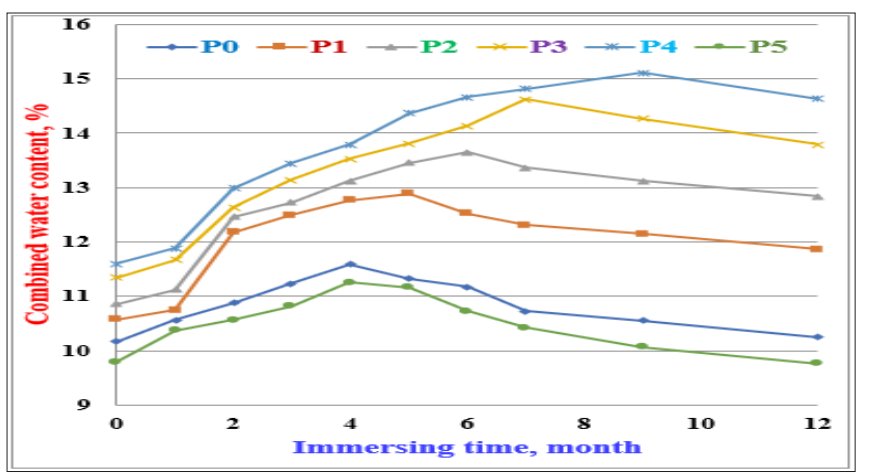

Figure 6: Combined water contents of the OPC cement pastes $(\mathrm{Pp} 0)$ with different contents of $\mathrm{PT}$ (Pp1-Pp5) immersed in 4\% MgSO4 solution up to 12 months.

\section{Compressive strength}

The compressive strength of the hardened cement pastes with and without PT (Pp0-Pp5) immersed in $4 \%$ sulfate solution $\left(\mathrm{MgSO}_{4}\right)$ are represented as a function of immersing time up to 12 months in Figure 7. The compressive strength of the hardened cement pastes of the OPC (Pp0) increased slightly only up to 3 months, and then slightly decreased up to 6 months, but sharply decreased up to 12 months of immersion, i.e. the 28-days compressive strength of the plain OPC pastes (Pp0) can withstand in $4 \% \mathrm{MgSO}_{4}$ for up to three months. This is mainly due to that at early stages of immersion, the total porosity of the hardened cement pastes is nearly the maximum. Therefore, the rate of diffusion of sulfate ions could be partially eliminated and only form a white sheet on the lateral surfaces of the specimens which hinders the penetration of the sulfate ions through the cement surfaces [19]. So, a slight gradual increase in the compressive strength due to the normal hydration process and also to the slight activation of sulfate ions $[9,15,19]$.

The decrease of compressive strength after 3 months of immersion is essentially attributed to the aggressive attack of sulfate ions so that the cement pastes could not resist the diffusion of $\mathrm{SO}_{4}^{-2}$ ions inside the matrix of cement pastes more than three months. This offered a big chance to occur some detrimental reactions ended by the formation of a large quantity of ettringite and/or gypsum. The latter phases often cause expansion followed by internal minor cracks and the disintegration of the formed hydrates, which are the centers of binding or cementing properties. These are the main factors of the strength loss $[2-4,16,19]$.

The compressive strength of the hardened cement pastes containing various proportions of PT up to 20wt \% (Pp1-Pp4) immersed in $4 \% \mathrm{MgSO}_{4}$ solution increased with immersing time up to 4, 5, 6 and 7 months, respectively and then decreased onward up to 12 months as shown from Figure 7. The increase of compressive strength is primarily contributed to the deficiency of the OPC phases, particularly $\mathrm{C}_{3} \mathrm{~A}$, which are so very sensitive to sulfate ions that they are easily degraded by these ions. It was compensated by the pozzolanic reactions of PT with the evolved free lime, Ca $(\mathrm{OH})_{2}$ coming from the hydration process of $\mathrm{C}_{3} \mathrm{~S}$ and $\beta-\mathrm{C}_{2} \mathrm{~S}$ of the cement [44]. Moreover, the active silica nano particles from PT are difficult to disintegrate easily by the $\mathrm{SO}_{4}^{-2}$ ions at the early stages of immersion due to its high amorphous glassy structure. Therefore, as the PT content increased, the durability increased too, in addition to the slight activation of the OPC by the active silica of PT. Also, the good dispersion with the lignosulfonate admixture and the good compaction during moulding helped to enhance and improve the strength development due to its strong filling action [44-47]. The relatively lower amount of free lime due to its consumption by PT to form CSH made the rate of sulfate ions penetration into the hardened cement pastes was the minimum because it reduces the permeability [44]. Adámek and Juránkova [45] concluded a similar result where the Fly Ash (FA) could be created soft parts of fresh cement pastes which improved its plasticity, infilled gaps among ingredients, compressed the contact zone among the different grains and the matured cement. Also, the hydraulic features of FA especially contributed to the mechanical strength enlargement. Also, the decrease of permeability to $\mathrm{SO}_{4}^{-2}$ ions seemed to improve the durability.

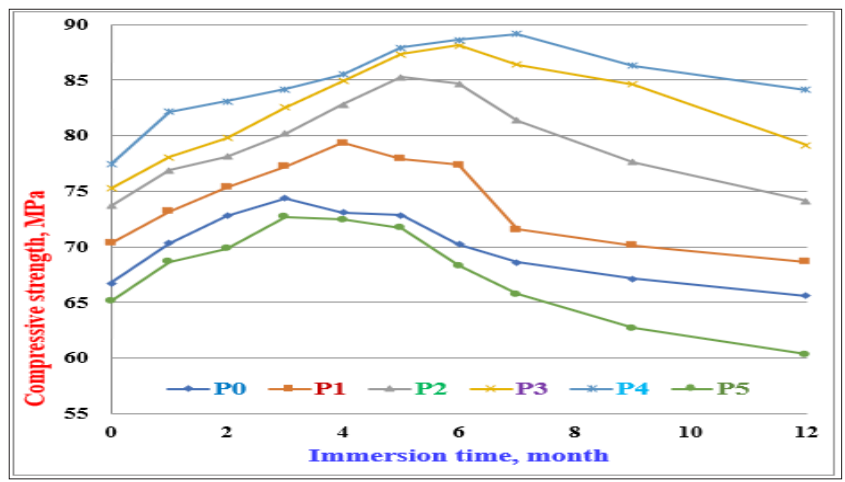

Figure 7: Compressive strength of the OPC cement pastes (Pp0) with different contents of PT immersed in 4\% MgSO4 solution up to 12 months.

As a result, the compressive strength tends to increase $[42,46,47]$. The same trend was displayed with all cement pastes according to the PT content, i.e. they were exhibiting various values of compressive strength. As it was mentioned previously, the decrease of the compressive strength of the immersed cement pastes in $\mathrm{SO}_{4}^{-2}$ ions is mainly attributed to the aggressive attack of the $\mathrm{SO}_{4}^{-2}$ ions which made it to penetrate aggressively inside the matrix of the cement pastes and disintegrated the formed hydration products. This was the cause to decrease the compressive strength. The hardened cement pastes containing 20wt \%PT (Pp4) achieved the highest resistance against $\mathrm{SO}_{4}^{-2}$ ions attack up to 7 months, while that of Pp5 recorded the lowest resistance. This may be due to the higher amount of PT at the expense of OP reduced the rate of hydration. Also, the decrease of compressive strength may be due 
to the release of water from the cement pastes into the solution as a result of the detrimental reactions. This usually accompanied with a consequent increase in the porosity and permeability. This tends to speed up the action effect of $\mathrm{SO}_{4}^{-2}$ ions. Therefore, a strength loss would be expected $[4,9,32,48-50]$.

\section{Total sulfate content}

The total sulfate contents of the various cement pastes with and without PT (Pp0-Pp5) immersed in $4 \% \mathrm{MgSO}_{4}$ solution up to 12 months are graphically plotted as a function of immersing time in Figure 8. The total sulfate contents tended to increase with immersion time up to 12 months. This trend was displayed by all cement mixes. This is due to the migration of $\mathrm{SO}_{4}{ }^{2-}$ ions into the hardened cement matrix, which in turn reacted with aluminate, ferrite and $\mathrm{Ca}(\mathrm{OH})_{2}$ to form tricalcium sulfo-aluminate hydrates, $\mathrm{C}_{3} \mathrm{~A} .3 \mathrm{CaSO}_{4} .32 \mathrm{H}_{2} \mathrm{O}$ or ettringite and/or monosulfate hydrate, $\mathrm{C}_{3} \mathrm{~A}$. $\mathrm{CaSO}_{4} \cdot 12 \mathrm{H}_{2} \mathrm{O}[7,16,19,48-51]$. The cement composite containing 25wt. \%PT (Pp5) exhibited the highest values of total sulfate than those of other blended cement pastes nearly at all immersing times, whereas that of Pp4 containing 2wt \% PT (Pp4) recorded the lowest values. It is clearly noticed that the values of total sulfate contents of cement blends (Pp1-Pp4) are much lower than those of the blank (Pp0) due to the formation of a dense white coat of $\mathrm{SO}_{4}{ }^{2-}$ ions on the lateral surfaces of immersed samples. This coat hinders the penetration and diffusion of $\mathrm{SO}_{4}{ }^{2-}$ ions into the cement pastes to some extent. This in turn slows down the action effect of the $\mathrm{SO}_{4}{ }^{2-}$ ions $[5,7,49-52]$. This is in addition to other factors as the good dispersion by the used admixture and good compaction of samples during moulding. It is also clear that the values of total sulfate contents of Pp1-Pp4 are close to each other and are much lower than those of the blank (Pp0), i.e. the pure OPC pastes (Pp0) are so sensitive to $\mathrm{SO}_{4}{ }^{2-}$ ions that they are highly affected with these ions $[4,5,7,16,53,54]$.

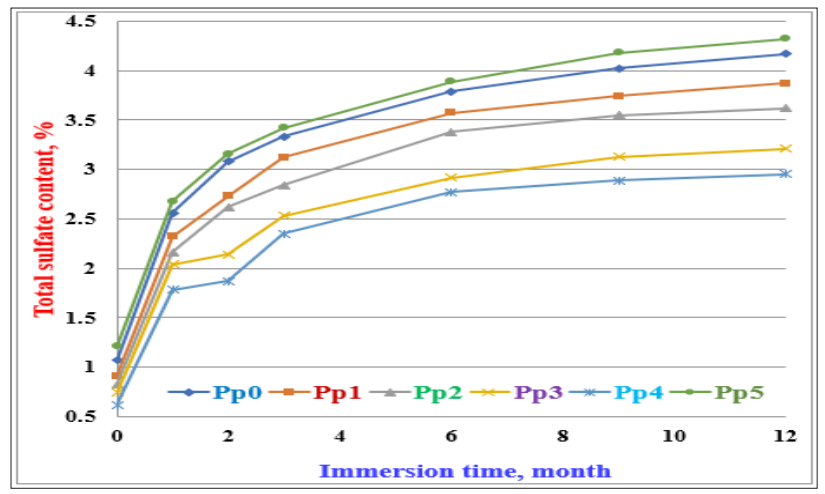

Figure 8: Total sulfate contents of the various cement pastes containing PT immersed in 4\% MgSO4 solution up to 12 months.

\section{Mechanism of reactions}

$\mathrm{MgSO}_{4}$ was always ionized to produce $\mathrm{Mg}(\mathrm{OH})_{2}$, which it is basic. So, the $\mathrm{SO}_{4}^{-2}$ ions are more effective particularly in older immersing times, which always dissociated into or through the matrix causing a more pore structure. This led to an increase in both porosity and permeability followed by a more strength loss $[15,42,43,51,52]$.
Also, the PT often hydrated inside the pastes by reacting with Ca $(\mathrm{OH})_{2}$. This seemed to decrease the $\mathrm{pH}$ value of the pastes. Therefore, the cement pastes are accordingly attacked leading to a decrease in the compressive strength $[9,15,49,53]$. Consequently, the Pp5 is the most and strongest negatively effective with $\mathrm{SO}_{4}^{-2}$ ions, while the Pp1-Pp4 are the least effective on the resistance and durability of the cement pastes. This was agreed perfectly with that suggested by many investigators [2,25-28,51-54].

Though the $\mathrm{SO}_{4}^{-2}$ ions attacked the cement pastes aggressively after the $9^{\text {th }}$ month of immersion, no visual cracks or any signs of deterioration on the lateral surfaces or edges could be seen by the naked eyes, but at the end of the $12^{\text {th }}$ month of immersion, the $\mathrm{SO}_{4}{ }^{2-}$ ions only precipitated or adsorbed on the external surfaces of the hardened cement pastes, and some horizontal minor cracks and little deformation could be seen on the edges of specimens, where large cracks and swelling were noted with cement pastes of the blank (Pp0). Consequently, it could be concluded that Pp4 has the best degree of resistance, while Pp5 exhibited the lowest [48-54].

During the early stages of immersion in $\mathrm{MgSO}_{4}$ solution, it soon reacted with the resulting free lime, $\mathrm{Ca}(\mathrm{OH})_{2}$ from the normal hydration of calcium silicate phases of the cement in the presence of water to produce gypsum $\left(\mathrm{CaSO}_{4} \cdot 2 \mathrm{H}_{2} \mathrm{O}\right)$ and brucite, $\mathrm{Mg}(\mathrm{OH})_{2}$ or magnesium hydroxide as follows:

$$
\mathrm{MgSO}_{4}+\mathrm{Ca}(\mathrm{OH})_{2}+2 \mathrm{H}_{2} \mathrm{O} \rightarrow \mathrm{CaSO}_{4} \cdot 2 \mathrm{H}_{2} \mathrm{O}+\mathrm{Mg}(\mathrm{OH})_{2} \longrightarrow 5
$$

The formed brucite or $\mathrm{Mg}(\mathrm{OH})_{2}$ is insoluble and often decreases the $\mathrm{pH}$-value of the hydration products. Hence, the reduction of $\mathrm{pH}$ value de-stabilized either $\mathrm{CSH}$ or ettringite, $\mathrm{C}_{3} \mathrm{~A} .3 \mathrm{CaSO}_{4} .32 \mathrm{H}_{2} \mathrm{O}$. Furthermore, there is no additional ettringite is produced because the $\mathrm{MgSO}_{4}$ ions further reacted with $\mathrm{CSH}$ to form additional gypsum, $\mathrm{Mg}(\mathrm{OH})_{2}$ and $\mathrm{SiO}_{2}$-gel $[44,45]$ as follows:

$$
\mathrm{MgSO}_{4}+\mathrm{C}_{x} \mathrm{~S}_{y} \mathrm{H}_{z}+(3 x+0.5 y-z) \mathrm{H}_{2} \mathrm{O} \rightarrow \mathrm{CaSO}_{4} \cdot 2 \mathrm{H}_{2} \mathrm{O}+\mathrm{Mg}(\mathrm{OH})_{2}+\mathrm{SiO}_{2}-\mathrm{gel} \longrightarrow 6
$$

The latter phase $\left(\mathrm{SiO}_{2}\right.$-gel) has less or no cementing properties than $\mathrm{CSH}$ and/or CAH. These hydrates continue to hydrate liberating free lime, $\mathrm{Ca}(\mathrm{OH})_{2}$ to re-increase the $\mathrm{pH}$-value and establish its equilibrium. But, the liberated free lime instead of re-increasing the $\mathrm{pH}$-value, it reacts with $\mathrm{MgSO}_{4}$ ions to form additional $\mathrm{CaSO}_{4}$. $2 \mathrm{H}_{2} \mathrm{O}$ and $\mathrm{Mg}(\mathrm{OH})_{2}$, and so on. As a result, the levels of $\mathrm{CaSO}_{4} \cdot 2 \mathrm{H}_{2} \mathrm{O}$ and $\mathrm{Mg}(\mathrm{OH})_{2}$ gradually increased, whilst the CSH lost its cementing properties. This would be led to more deleterious effects. Furthermore, the formed $\mathrm{Mg}(\mathrm{OH})_{2}$ reacted again and again with the $\mathrm{SiO}_{2}$-gel to form magnesium silicate hydrate, $\mathrm{MSH}$ as follows:

$$
4 \mathrm{Mg}(\mathrm{OH})_{2}+\mathrm{SiO}_{2}-\mathrm{gel} \rightarrow \mathrm{MSH} \longrightarrow 7
$$

If the later resulting product (MSH) is formed, it will cause softening or dusting of the cement pastes. This is mainly due to its non-cementitious properties [52-54]. Hence, the damaging effect is mainly due to the formation of high amounts of gypsum and Sodium hydroxide, and finally MSH [46-48].

\section{Conclusion}

The water of consistency as well as setting times of the various cement batches was increased with the increase of PT content. 
The compressive strength of the hardened cement pastes of the (Pp1-Pp4) are in a good agreement with combined water and total sulfate contents. The hardened cement pastes containing perlite (Pp0-Pp5) showed the higher resistance against $4 \% \mathrm{SO}_{4}{ }^{2-}$ ions up to 4, 5, 6 and 7 months according to the PT content if compared with those of the corresponding pure OPC pastes (Pp0), where it could not withstand except only up to three months of immersion. The most and strongest effect of $\mathrm{SO}_{4}{ }^{2-}$ ions, started to occur after seven months. The total sulfate contents increased with immersing time up to 12 months but decreased with PT content. The same trend was displayed by all cement batches. Consequently, the degree of damage was in the descending order: Pp4 > Pp3 > Pp2 > Pp1 > Pp0 $>$ Pp5. The cement batch (Pp4) containing 20wt. \% PT achieved the best resistance against sulfate solution, whereas that of Pp5 exhibited the lowest. As it is well seen from the results, the OPC/ PT cement composites are more resistant to sulfate solution than the pure OPC cement (Pp0).

\section{Acknowledgement}

Author wishes to express their deep thanks to National Research Centre for helping to obtain materials, processing, preparing, molding and measuring all of the obtained data of the study, and moreover for financial assistance.

\section{Conflict of Interest}

The author declines that there is no conflict of interest anywhere.

\section{References}

1. Ghazizadeh S, Duffour P, Skipper NT, Bai Y (2018) Understanding the behaviour of graphene oxide in Portland cement paste. Cement and Concrete Research 111: 169-182.

2. Said AM, Zeidan MS, Bassuoni MT, Tian Y (2012) Properties of concrete incorporating nano-silica. Construction and Building Materials 36: 838844.

3. Yu R, Spiesz P, Brouwers HJH (2014) Effects of nano-silica on the hydration and microstructure development of Ultra-High-Performance Concrete (UHPC) with a low binder amount. Construction and Building Materials 65: 140-150.

4. Sharma U, Singh LP, Zhan B, Poon CS (2019) Effect of particle size of nano-silica on microstructure of C-S-H and its impact on mechanical strength. Cement \& Concrete Composites 97: 312-321.

5. Neville AM (2011) Properties of Concrete. ( $5^{\text {th }}$ edn), UK.

6. Zareei SA, Ameri F, Dorostkar F, Ahmadi M (2017) Rice husk ash as a partial replacement of cement in high strength concrete containing micro silica: Evaluating durability and mechanical properties. Case Studies in Construction Materials 7: 73-81.

7. Hewlett PC, Liska M (2017) Lea's chemistry of cement and concrete. ( $5^{\text {th }}$ edn), London.

8. Nehdi M, Hayek M (2005) Behavior of blended cement mortars exposed to sulfate solutions cycling in relative humidity. Cem Concr Res 35(4): 731-742.

9. Darweesh HHM (2020) Characteristics of Portland cement pastes blended with silica nanoparticles. To Chemistry 5: 1-14.

10. Dulaijan SU, Maslehudin M, Zahrani MM, Sharif AM, Shameem M, et al. (2003) Sulfate resistance of plain and blended cements exposed to varying concentration of sodium sulfate. Cem Concr Comp 25(4-5): 429437.

11. Adesina A (2019) Durability enhancement of concrete using nanomaterials: An overview. Mater Sci Forum 967: 221-227.

12. Saloma A, Nasution I, Imran M (2015) Improvement of concrete durability by nanomaterials. Proc Eng 125: 608-612.

13. Santhanam M, Cohen MD, Olek J (2002) Mechanism of sulfate attack: A fresh look: Part I: Summary of experimental results. Cem Concr Res 32(6): 915-921.

14. Sideris KK, Sawa AE, Papayianni J (2006) Sulfate resistance and carbonation of plain and blended cements. Cem Concr Comp 28(1): 4756.

15. Aksoǵan O, Binici H, Ortlek E (2016) Durability of concrete made by partial replacement of fine aggregate by colemanite and barite and cement by ashes of corn stalk, wheat straw and sunflower stalk ashes. Construction and Building Materials 106: 253-263.

16. Reheem AA, Adedokun SI, Adeyinka EA, Adewole BV (2017) Application of corn stalk ash as partial replacement for cement in the production of interlocking paving stones. International Journal of Engineering Research in Africa 30: 85-93.

17. Binici H, Ortlek E (2015) Engineering properties of concrete made with cholemanite, barite, corn stalk, wheat straw and sunflower stalk ash. European Journal of Engineering and Technology 3(4): 23.

18. Binici H, Aksogan O (2006) Sulfate resistance of plain and blended cement. Cem Concr Comp 28(1): 39-46.

19. Sokkary EM, Assal HH, Kandeel AM (2004) Effect of silica fume or granulated slag on sulphate attack of ordinary Portland and alumina cement blends. Ceramics International 30(2): 133-138.

20. Didamony H, Darweesh HHM, Mostafa RA (2008) Characteristics of pozzolanic cement pastes Part I: Physico-mechanical properties. Sil Ind Cer Sci \& Techn 73(11-12): 193-200.

21. Darweesh HHM, Suoud MR (2019) Palm ash as a pozzolanic material for Portland cement pastes. Chemistry Journal 4: 72-85.

22. Feng P, Liu J, She W, Hong J (2018) A model investigation of the mechanisms of external sulfate attack on Portland cement binders. Construction and Building Materials 175: 629-642.

23. Adesanya DA, Raheem AA (2010) A study of the permeability and acid attack of corn cob ash blended cements. Construction and Building Materials 24(3): 403-409.

24. Zhu J, Jiang M, Chen J (2008) Equivalent model of expansion of cement mortar under sulphate erosion. Acta Mechanica Solida Sinica 21(4): 327-332.

25. Lee ST, Moon HY, Swamy RN (2005) Sulfate attack and role of silica fume in resisting strength loss. Cement and Concrete Composites 27(1): 6576.

26. Guo Z, Wang Y, Hou P, Shao Y, Zuo X, et al. (2019) Comparison study on the sulfate attack resistivity of cement-based materials modified with nano $\mathrm{SiO}_{2}$ and conventional SCMs: Mechanical strength and volume stability. Construction and Building Materials 211: 556-570.

27. Cho YK, Jung SH, Choi YC (2019) Effects of chemical composition of fly ash on compressive strength of fly ash cement mortar. Construction and Building Materials 204: 255-264.

28. Liu J, Yu Q, Zuo Z, Yang F, Han Z, et al. (2019) Reactivity and performance of dry granulation blast furnace slag cement. Cement \& Concrete Composites 95: 19-24.

29. Olsson N, Nilsson L, Bouny BV, Magnus A (2018) Moisture transport and sorption in cement-based materials containing slag or silica fume. Cement and Concrete Research 106: 23-32. 
30. Erdem TK, Meral C, Tokyay M, Erdogan TY (2007) Use of perlite as a pozzolanic addition in producing blended cements. Cem Concr Composites 29(1): 12-21.

31. Demirboga R, Örüng I, Gül R (2001) Effect of expanded perlite aggregate and mineral admixtures on the compressive strength of low-density concrete. Cem Concr Res 31(11): 1627-1632.

32. Darweesh HHM (2017) Utilization of perlite rock in blended cement-part I: Physico-mechanical properties. Direct Research Journal of Chemistry and Material Science 2(1): 1-12.

33. Yu LH, Ou H, Lee LL (2003) Investigation on pozzolanic effect of perlite powder in concrete. Cem Concr Res 33(1): 73-76.

34. Topçu IB, Ateşin Ö (2016) Effect of high dosage lignosulphonate and naphthalene sulphonate based plasticizer usage on micro concrete properties. Construction and Building Materials 120: 189-197.

35. ASTM-C187-86 (1993) Standard test method for normal consistency of hydraulic cement. pp. 148-150.

36. ASTM-C191-92 (1993) Standard test method for setting time of hydraulic cement. pp. 866-868.

37. ASTM-C170-90 (1993) Standard test method for compressive strength of dimension stone. pp. 828-830.

38. Nadesan MS, Dinakar P (2017) Mix design and properties of fly ash waste lightweight aggregates in structural lightweight concrete. Case Studies in Construction Materials 7: 336-347.

39. Karim MR, Zain MFM, Jamil M (2012) Strength of mortar and concrete as influenced by rice husk ash: A review. World Applied Sciences Journal 19(10): 1501-1513.

40. Provis JL (2018) Alkali-activated materials [J]. Cement and Concrete Research 114: 40-48.

41. Chusilp N, Jaturapitakkul C, Kiattikomol K (2009) Utilization of bagasse ash as a pozzolanic material in concrete. Constr Build Mater 23(11): 3352-3358.

42. Zyganitidis I, Stefanidou M, Kalfagiannis N, Logothetidis S (2011) Nanomechanical characterization of cement-based pastes enriched with $\mathrm{SiO}_{2}$ nano-particles. Mater Sci Eng B 176(9): 1580-1584.
43. Jiang L, Niu D (2016) Study of deterioration of concrete exposed to different types of sulfate solutions under drying-wetting cycles. Constr Build Mater 117: 88-98.

44. Sideris KK, Sawa AE, Papayianni J (2006) Sulfate resistance and carbonation of plain and blended cements. Cem and Concr Comp 28(1): 47-56.

45. Ghafoori N, Batilov I, Najimi M (2017) Influence of dispersion methods on sulfate resistance of nano silica-contained mortars. J Mater Civ Eng 29(7).

46. Diab AM, Elyamany HE, Elmoaty AEM, Sreh MM (2019) Effect of nanomaterials additives on performance of concrete resistance against magnesium sulfate and acids. Constr Build Mater 210: 210-231.

47. Adeyemi A (2020) Nanomaterials in cementitious composites: Review of durability performance. Journal of Building Pathology and Rehabilitation 5: 21.

48. Palla R, Karade SR, Mishra G, Sharma U, Singh LP (2017) High strength sustainable concrete using silica nanoparticles. Constr Build Mater 138: 285-295.

49. Lawrence CD (1990) Sulphate attack on concrete. Mag Concr Res 24: 249-257.

50. Camacho RER, Afif UR (2002) Importance of using natural pozzolans on concrete Durability. Cem Concr Res 32(12): 1851-1858.

51. Wee TH, Suryavanshi AK, Wong SF, Rahman KMA (2000) Sulfate resistance of concrete containing mineral admixtures. ACI Mater J 97(5): 536-549.

52. Nehdi M, Hayek M (2005) Behavior of blended cement mortars exposed to sulfate solutions cycling in relative humidity. Cem Concr Res 35(4): 731-742.

53. Kumar A, Jain S, Tyagi BS (2018) Experimental and comparative study of compressive strength of concrete with the use of nanosilica. Intern Res Journ Engineering and Technology 5(7): 1801-1806.

54. Huang Q, Zhao L, Zhao C, Liu D, Wang C (2020) Microstructure change of nanosilica-cement composites partially exposed to sulfate attack. Int J Concr Struct Mater 14(27): 2-11.

For possible submissions Click below: 